\title{
A FRAMEWORK FOR ENHANCING THE RESPONSIVENESS TO DEFECTS VIA SPC AND WORKER EMPOWERMENT
}

\author{
Omayma A. Nada \\ Production Engineering and Mechanical Design Department, Faculty of Engineering, \\ Menoufia University, Shebin El-kom, Menoufia, Egypt.
}

\begin{abstract}
:
The ultimate goal of the online quality control initiatives is to prevent the occurrence of defects or rather to detect the occurrence of defects as fast as possible in order to interfere with corrective actions. Generally, Statistical Process Control (SPC) tools such as control charts can be effectively applied to monitor the production processes and can be used as an indicator for the occurrence of assignable causes in the process which are mainly responsible for the occurrence of defects. Typically, the out of control signals resulted from control charts or other signs of developing defective items that are observed directly through visual inspection necessitate a rapid response from the shop floor operators. Meanwhile, the lack of worker empowerment and poor communication between shop floor workers and engineers as well as managers are mainly responsible for the late decisions and actions which lead to increased defect rates. This paper presents a framework that integrates SPC approaches with worker empowerment practices to enhance the responsiveness toward detected defects as well as preventing the occurrence of more ones. Besides, a case study concerned with the manufacturing of Unplasticized Polyvinyl Chloride (UPVC) pipes has been conducted to demonstrate the application of the proposed framework.
\end{abstract}

Keywords: Statistical Process Control (SPC), Control charts, worker empowerment.

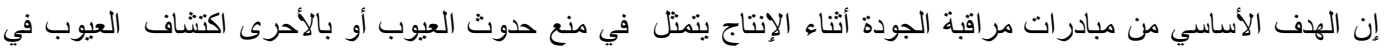

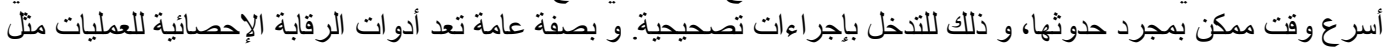

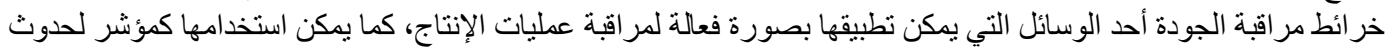

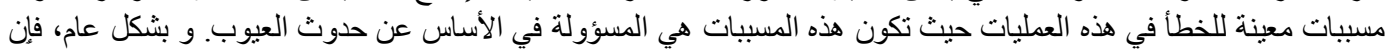

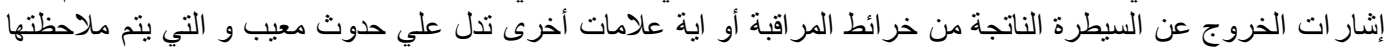

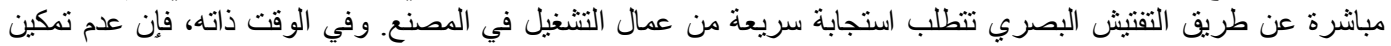







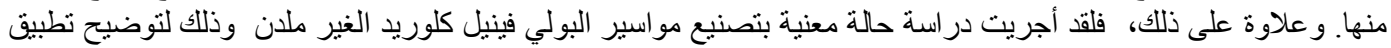
إطار العمل المقترح. 


\section{INTRODUCTION}

For several decades Statistical Process Control (SPC) tools such as control charts have been effectively employed to monitor the performance of production lines. Control charts are mainly designed to distinguish between random cause variations and special cause or assignable cause variations. Consequently, these tools can serve as defect avoidance techniques, not just defect detection oriented approaches. They provide the user with the advantage of acting on the process in a preventive manner and give the chance for correcting possible process deviations in real time. The out of control signals appear in the control charts have the advantage of alarming for special causes of variation that should be handled as soon as they occur in order to avoid producing nonconforming units [1].

It should be pointed out that the implementation of SPC does not only entail constructing charts, but also it should be accompanied by changing the organization's culture and environment in order to exploit the full potential of such tools [2]. Unfortunately, the lack of communication among engineers, managers, and shop floor operators might hinder the effectiveness of SPC as proactive tools. Shop floor operators should be trained and empowered to be more responsive in terms of the corrective actions affecting their processes. People in industry are usually faced with the dilemma that personnel who grasp the practices of control charts are not in charge of fixing the processes. In the meanwhile, personnel who can fix the processes are not familiar with interpreting the control chart signals. In these scenarios, the management philosophy and human behavior issues, including resistance to change are key factors for delaying decisions related to corrective actions [3].

Not only errors detected from control charts, but also nonconformities observed during visual inspection necessitate worker interference to resolve the expected issues causing such problems. One of the successful practices that have been widely implemented for this purpose is Autonomation. In which, a technology for detecting defects as they occur and automatically stopping the production so that the operator can fix the problem before more defects are generated and proceed to the next stage of production. Even though, if the company does not have the technology to automatically detect defects and it relies only on worker's observations, workers must have the authority to stop the line. For instance, in Toyota Production Systems (TPS), workers have the power to stop the line through pulling an "Andon cord" to prevent the propagation of the problem [4]. If the line is not equipped with an Andon cord, the worker should have a set of instructions to quickly respond to such situations. It has been widely approved that building the quality into the system and preventing the occurrence of defects is preferred over inspecting to catch defectives. The quality guru Crosby in his famous book "Quality is Free" argued that what actually costs money is something called un-quality and the consequent actions as well as resources that resulted due to not doing the job right the first time. This implies that companies should strive to employ defect prevention approaches as well as empower workers to detect and correct problems at the source rather than inspecting to locate defective products after the fact $[5,6]$. Accordingly, the higher the responsiveness toward the defect occurrence and resolving the problems as soon as they happen, the lower the costs associated with bad quality and the lower the non-value added resources to be wasted.

This paper presents a framework that integrates statistical process control approaches with worker empowerment to achieve more effective process monitoring. The ultimate objective of the proposed framework is to deal with detected out of control signals as well as visually observed defects in a more responsive manner. The framework has been applied to a case study conducted at one of the leading Egyptian companies in the field of plastic pipes and fittings manufacturing. Generally, the company's products are well recognized and are widely installed in several domestic water systems such as water distribution, water treatment, irrigation systems, and in all types of industrial process pipe works. The case study aims at investigating the production process of one of the company's products and assessing the current practices that the company uses for the online process control and their effectiveness. The objective of the conducted case study is to implement the appropriate control charts to monitor the production process. In addition, recommendations that can help in increasing the responsiveness toward the detected defects have been proposed.

The remainder of this paper is structured as follows: Section 2 presents a review of the relevant literature. Section 3 introduces the methodology to be adopted as it explains in details the proposed framework. Section 4 provides a case study that demonstrates the implementation of the presented framework. Section 5 is allocated to the results and discussion. Finally, Section 6 is devoted to the conclusions and recommendations.

\section{LITERATURE REVIEW}

\subsection{Statistical Process Control}

Statistical Process Control (SPC) is concerned with the application of statistical techniques for the sake of monitoring and controlling the behavior processes. Definitely, when SPC is employed appropriately, it can effectively enable the process owners to prevent problems and properly control their processes [7]. Particularly, in manufacturing processes, the purpose of SPC is to immediately recognize when the quality starts to diverge from a 
predefined quality standard. Control charts as the key tool in SPC are basically designed to record the manufacturing process continuously and thereby they are mainly directed to examine and maintain the stability of the manufacturing process under investigation. However, despite the wide application of SPC tools in several domains, it is unlikely to gain its full potential unless it is implemented within an effective management environment [8].

The SPC tools, particularly the control charts have been extensively adopted in diverse industrial sectors. For example, the process stability and capability have been assessed in a pharmaceutical company as a part of the implementation of a six sigma project. Typically, as an essential step in assessing the process state of control, Xbar-R charts have been constructed for the active pharmaceutical ingredient concentration in product tablets [9]. While, in the food industry, the cumulative sum control chart (CUSUM) and the Exponentially Weighted Moving Average (EWMA) charts have been developed as a part of the quality monitoring process for chicken wings. Specifically, the critical parameters that have been monitored using control charts include the weight of the chicken wings, the sterilizer temperature, as well as the grid-pan temperature [10]. Whereas, during the DMAIC (define-measure-analyze-improve-control)

implementation for improving the process capability in tire manufacturing, Xbar-R charts have adopted for monitoring the bead splice variation [11]. Similarly, Xbar-R charts have been employed in the process of cutting predefined lengths of semi-rigid coaxial-collinear cable during a pilot study for SPC implementation in a small organization. During the study, the average and range charts have been constructed to track the deviation of the length from its nominal value. The developed charts effectively assisted the operation personnel in eliminating the assignable causes of variation and significantly helped in reducing the non-conforming products as reported in [12]. Alternatively, the time series modeling and the EWMA control charts have been utilized for gearbox fault detection. To do so, the control limits of the EWMA chart have been established for a healthy gear tooth, then the data are plotted against those control limits to monitor the deviations in the feature values and to identify the out of control signals. It has been justified that the developed charts could serve as a condition monitoring tool in similar applications due to their responsiveness and sensitivity to faults' severity [13].

Additionally, it should be pointed out that the implementation of SPC mainly started in the manufacturing processes and then it has been deployed in several other applications. For instance, SPC has been applied to the medical sector in a wide range of situations and specialties at diverse levels of organizations for various variables. A review of the literature concerned with the application of SPC, with control charts as its core tool, in health care quality improvement has been provided in Ref. [14]. While in the service sector, SPC has been employed to improve the quality and efficiency of the processes in a restaurant. In particular, individual Moving Range (I-MR) chart and Moving Average (MA) chart have been employed to monitor the food freshness and quality [15]. However, in order to statistically monitor the topological features of the transportation network through time, a process control chart has been developed. Specifically, the CUSUM control charts have been constructed to monitor the closeness centrality of a transportation network through time and to detect the uncommon patterns due to extreme events [16].

\subsection{Worker Empowerment}

Generally, there is no consensus on the definition of empowerment in literature. However, some researchers refer to empowerment as the degree of taking the initiative and responding to overcome work related problems. Others, define the employee empowerment as the degree of enabling employees to make decisions related to their work or to assume the responsibility for their decisions and actions [17]. In particular, worker empowerment may be defined as providing workers with the necessary training and authority needed to manage their jobs. Several researchers emphasized that worker empowerment is critical in improving the in-process quality control. Empowering workers give them the chance to take the responsibility for their own work and proactively solve work problems as soon as recognized. Consequently, costs of quality can be significantly reduced due to the responsive detection and correction of errors during the production instead of waiting to the end of processing. Empowered shop floor workers are encouraged and aided to timely interfere to prevent or detect errors during the production rather than depending on final inspections. Moreover, they should be rewarded for their responsiveness in identifying and fixing production problems [18].

In order to help workers identify and solve quality problems as they appear on the line, they must have both a conceptual understanding of the process as well as the analytical skills to identify the root cause of the problems. Accordingly, a decentralized responsibility from specialized inspectors to production workers is required. Besides, a wide range of multi-skill practices is also necessary. This necessitates extensive job training, working in teams, as well as job rotation [19].

In one of the studies, the authors provided general guidelines on how people and technology can be integrated into manufacturing environments. Besides, they proposed transferring of responsibility for the product quality from the technical staff to the 
manual operators. Further, they reported that the gains of doing so are not only defect reduction, but also other goals are achieved including, improved worker performance, as well as job satisfaction [20]. On the other hand, six cases have been investigated to explore the characteristics of empowerment and how its level can be assessed via a role allocation model accompanied by worker effect on different dimensions of the company. The considered cases involve operators with their main tasks are concerned with machining, processing of products, or final assembly. The empowerment levels, according to work tasks have been highlighted [21].

In addition, the impact of empowerment on the organization productivity improvements has been recognized and reported in a longitudinal study that targeted to investigate the relative merits of some practices including empowerment [22]. Furthermore, it has been pointed out that empowerment practices can be established to reduce the high costs of monitoring and directing work activities [23]. Besides, it has been emphasized that empowerment cannot exist without well-trained workers and they will not be fully empowered until participating in process design decisions. Further, it has been demonstrated that gains from the empowerment of production workers can be realized in the long term. Therefore, short term efficiency based measures should not be the focus of the organization in their assessment of empowerment practices [24].

In spite of the reported advantages of empowering workers to fix problems as identified, managers and engineers should be cautious about informing the workers when they have to ask for help before making decisions. In some manufacturing sites, the striking note about the need for occasionally calling for assistance is that it is typically counterintuitive to managers who have been accustomed to workers fixing their processes without asking for help. In such an environment, problems may continue to remain hidden and they are not either shared or resolved companywide. Inversely, the situation may become even worse when workers start to inappropriately solve every problem they face and arbitrarily decide whether the problem is critical enough to deserve a call for help or not. Accordingly, problems may start to accumulate and only can be fully recognized so late that vital evidence about their actual causes may have been unseen anymore [25].

\section{METHODOLOGY}

This paper presents a framework that can be applied in order to monitor production processes using control charts assisted by empowered workers. The procedure, as demonstrated in Fig. 1, starts with the process investigation and the different characteristics to be monitored will be identified and classified into two main different sets. The first category includes the critical-to-quality variables and attributes to be monitored using statistical process control. In which, the appropriate control charts will be employed to assess the stability of the process. Any out of control signals will be identified and the workers should be trained to interpret the control chart and should be capable of employing the out of control action plans. The workers are also empowered to stop the production line if needed to resolve the condition that triggered the out of control signal. The quick response to the out of control signals associated with the prompt elimination of the assignable causes has the advantage of decreasing the chances of generating nonconforming output. The second category is concerned with the features and conditions that should be monitored via worker's vigilance. These include any distortion, damage, or any abnormal trend either in the process or in the output, as well as quality characteristics that are visually inspected. The proposed procedure targets to compensate for or simulate the autonomation or the jidoka practice in Toyota Production System (TPS) [26]. In such systems, the inspection activities are designed to be combined with the operations and the machine are equipped with intelligent mechanisms that are capable of instantaneously detecting abnormalities. After detection, the machines either stop automatically or provide warning signals. Since not all the factories have such technology or can justify the cost associated with purchasing new equipment, it is recommended in cases of visually inspected features and cases of abnormalities to rely on workers' surveillance. Besides, the workers should be empowered to interfere in a responsive manner as needed.

In the proposed framework, the cases in which abnormalities are expected to continue to produce nonconforming items or cases of out of control signals, the worker should be empowered to stop the machine immediately as needed. They have to be trained to investigate and resolve problems. If they successfully solved the problem by themselves, they are asked to put the system back to work and notify the management with a detailed report with the problem and its identified causes. If they failed to handle the situation, they are directed to ask for help from the engineers and managers. After fixing the problems and eliminating assignable causes, the control charts should be revised and state of control of the system should be continuously monitored. 


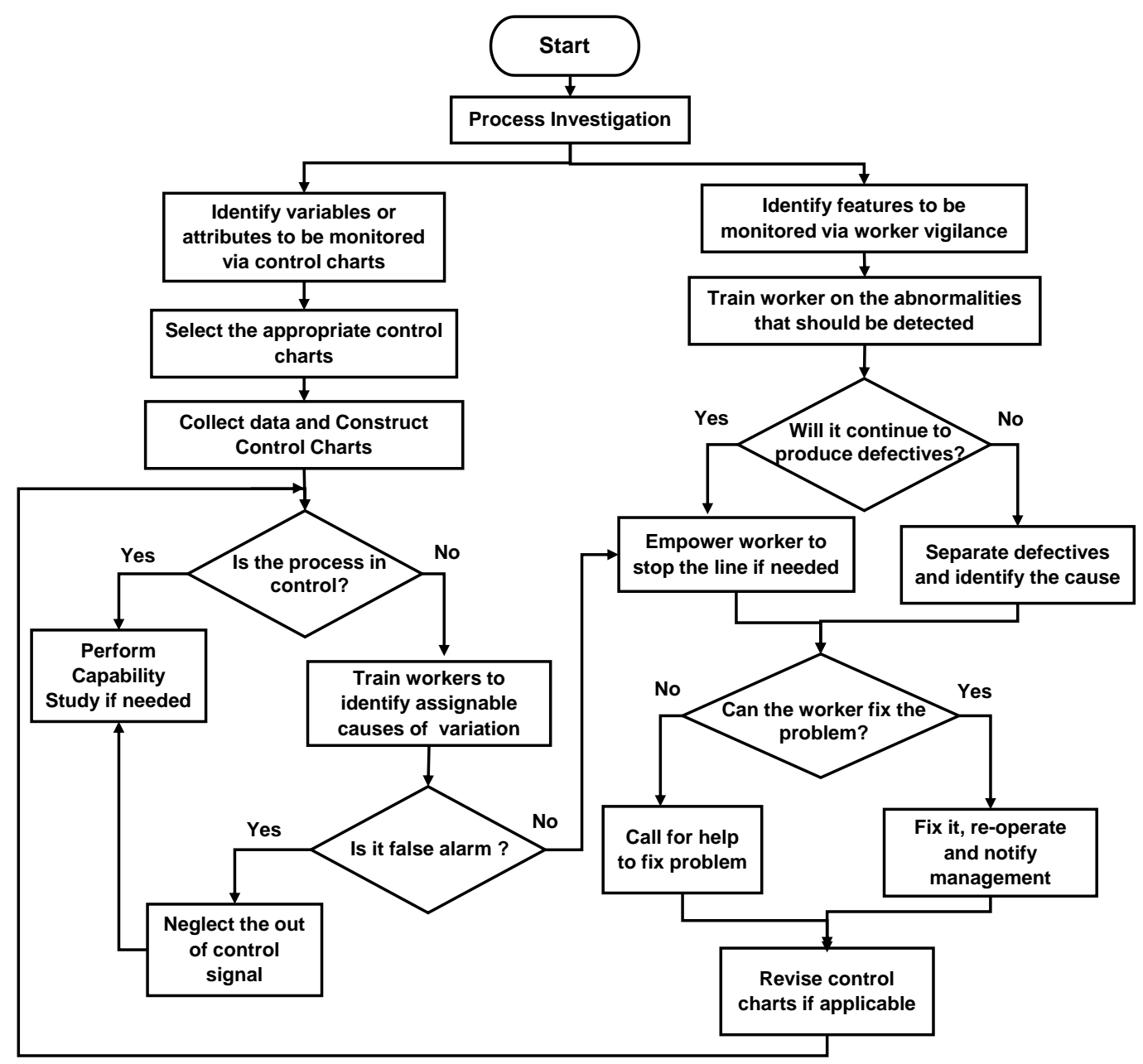

Fig. 1. A roadmap for process monitoring using SPC assisted by empowered workers

\section{CASE STUDY}

The application of the framework presented earlier on a case study conducted at one of the eminent Egyptian companies in the field of plastic pipes and fittings manufacturing will be presented in this section. The case study targets investigating the extrusion process concerned with manufacturing of the non-pressure unplasticized polyvinyl chloride (UPVC) pipes that are utilized for underground drainage and sewerage. These are also known as drain-waste-vent (DWV), which constitutes a part of the systems that get rid of sewage and greywater from buildings and regulates air pressure in the pipes' systems. More specifically, the case study considers the DWV-UPVC pipe extrusion with a nominal diameter of $110 \mathrm{~mm}$ and a wall thickness of $4 \mathrm{~mm}$. The manufacturing process of the considered product has been profoundly investigated.

Generally, in order to manufacture such a pipe, several processing stages have to be performed. Initially, the pipe manufacturing starts with mixing the raw material with some additives in predefined ratios. This process is performed using a special mixer and it takes place in a separate area attached to the production lines. The mixture weight per load is about $400 \mathrm{~kg}$ and the operators are directed to use mixing time that ranges between 7 to 10 minutes. The mixture is then pulled to the transfer tube that fills a big container with a capacity of 1.2 tones. In order to check that the mixture conforms to the specifications, a quality inspector takes three samples of 100 grams for each sample. The three samples are taken from the top, the middle, and the bottom of each container. The common practice is to check about 4 to 5 containers in every eight-hour shift. Several quality checks are performed to assure that the mixture conforms to specification before using it in the production. In case of finding a nonconforming sample, the whole container will be rejected. Consequently, the frequency of inspection should be increased to include $50 \%$ of all the containers. In case of detecting another rejected container, all the prepared mixture during this period of time will be rejected. After inspecting the raw material, the mixture containers are transferred to the production lines. 
In the pipe extrusion line, a vacuum conveyor transfers raw mixture into a hopper that continuously feeds down into the extruder. Next, the mixture is pushed into the extruder by a screw along a barrel so that the material is homogeneously heated in the heating zone. Then, the fused material is pushed through a die and mandrel where the pipe formation takes place. Afterwards, the pipe is cooled in a closed cooling system which is followed by stamping the tube with the essential identification data. To finish, it passes through a cutting unit to be cut to a predefined length as needed by the customer.

Examining the quality control procedures associated with the manufacturing of the considered pipe reveals that several quality checks are performed at the end of line. Some of these checks are performed on samples of the final product inside the shop floor while the process is still continuously running on the same pipe type. These include the outside diameter and the thickness of the pipe. While, other checks necessitate that the drawn samples should be sent to the lab to prepare specimens to be tested on different special devices. These include the strength, impact strength, resistance to external blows, heat reversion, as well as resistance to dichloromethane. In addition to irregularities, cracks, and any other defects visually observed by workers. It should be pointed out that the company uses International quality standards in manufacturing and testing their products. However, investigating the current company's quality control practices discloses that there is a lack of the implementation of some approaches that could enhance the process monitoring. Particularly, there are no statistical process control tools deployed for assessing the state of control of the process and providing alarms for assignable causes of variation in the process. Besides, workers observing the production process can visually identify the imperfections of the output such as obvious distortion in pipes. However, they are not allowed to interfere and stop the production and prevent the occurrence of more defective pipes that will be definitely scraped. Alternatively, they are directed to just notify the supervisor who should convey the note to the engineers to make the decision of stopping the line in most of the cases. Consequently, this paper adopted the framework presented in the previous section to be employed for more effective process monitoring.

\section{RESULTS AND DISCUSSION}

Since the main target of the procedure to be implemented is either to prevent defects and/or to be more responsive to the detected ones, the quality characteristics that cannot be measured or assessed online will not be considered in this application. For instance, the samples collected for testing the mechanical properties of the produced pipes are not candidates for process monitoring using control charts in this case. This is because it needs a relatively long time compared with process speed to prepare specimens and perform these tests. Hence, only the pipes' outside diameter and wall thickness will be considered for monitoring using control charts. In order to monitor these variables, samples of data have been collected for the two variables. The common practice in the production line is to draw samples of five pipes every thirty minutes. In measuring the external diameter and the wall thickness of the produced pipes, the factory performs the measurements in accordance with the international standard ISO 3126 [27]. In performing the analysis for this case study, the Minitab Statistical Software (version 17) [28] will be utilized. Before starting to construct the control charts to monitor the process, the collected data sets have to be carefully examined. First of all, one has to check for autocorrelation in the observations of each individual variable. This is because the existence of autocorrelation can adversely affect the performance of the control charts in terms of dramatically increased false alarm rates [29]. To do so, the time series for the pipes' external diameter and wall thickness have been plotted as illustrated in Fig. 2 and Fig. 3, respectively. Besides, analysis of the autocorrelation function (ACF) test for the two variables has been performed and it has been verified that both of the external diameter and the wall thickness observations have no significant autocorrelation for any lags within the $95 \%$ confidence limits as shown in Fig. 4 and Fig. 5.

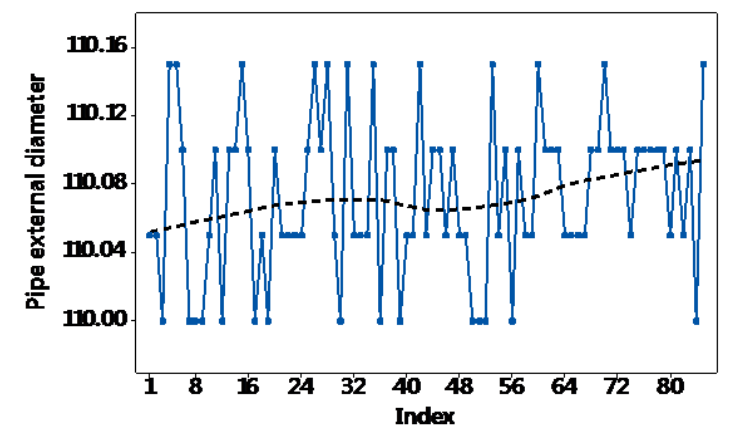

Fig. 2 Time series plot for pipe external diameter

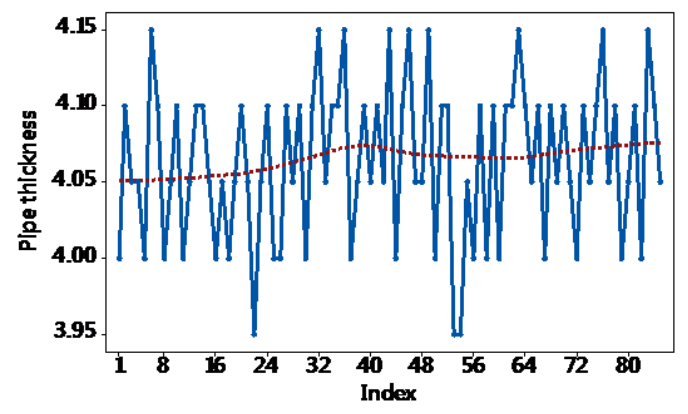

Fig. 3 Time series plot for pipe wall thickness 


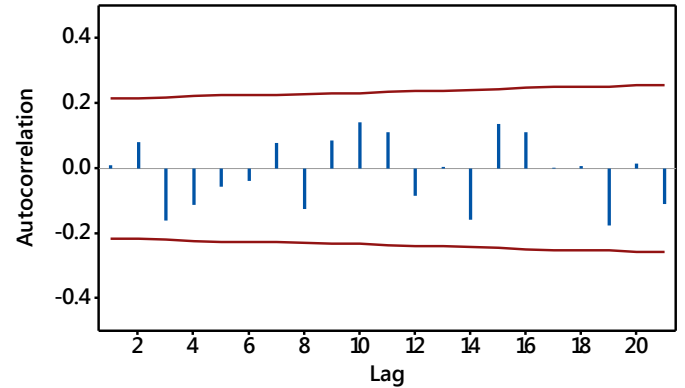

Fig. 4 ACF for external diameter (with 5\% significance limits for the autocorrelations)

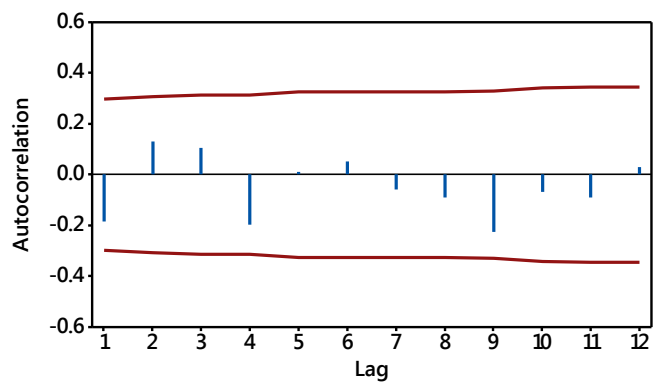

Fig. 5 ACF for thickness (with 5\% significance limits for the autocorrelations)

To monitor the two considered variables, a decision has to be made regarding whether to use multivariate or univariate control charts. Despite the advantages associated with using the multivariate control charts as opposed to the univariate ones as stated by several authors [30-32], the interpretation of the out of control signals in case of multivariate charts is not straightforward. This requires using further analysis, such as principal component analysis, to identify which of the variables are responsible for an out-of-control signal. Consequently, the implementation of multivariate control charts should not be considered unless the variables are strongly correlated [33]. Therefore, assessing the correlation between the variables is a critical step for such a decision. To decide whether one should use a univariate or multivariate chart, the coefficient of correlation between the variables along with a scatter plot has been developed.

To calculate the coefficient of correlation, the normality of the considered variables has to be assessed. Generally, the Anderson-Darling test is one of the tests that can be considered to determine if a data set follows a specified distribution [34]. In this application, this test has been applied to test for normality. The test involves calculating the Anderson-Darling (AD) statistic and then determining the $\mathrm{p}$-value for the statistic. For more details about this test, one may refer to [34]. Examining the probability plots, shown in Fig. 6 and Fig. 7, along with the p-value (using 5\% significance level) and the $\mathrm{AD}$ statistic values reveal that the null hypothesis that the data are from a normal distribution can be rejected for the two variables. Where, $\mathrm{p}$-value is the level of marginal significance within a statistical hypothesis test. Although the data are not normal, the Pearson coefficient of correlation can still be used as several authors have indicated its robustness to the normality of the data [35, 36]. Alternatively, Ref.[37] stated that the most frequent recommendation in the literature is to use the Spearman's rank-order correlation for non-normal data. In this study, the Spearman rho coefficient of correlation for thickness and diameter equals $(-0.030)$ with p-value $=0.786$. Examining these values, as well as the scatter plot illustrated in Fig. 8, it can be concluded that the correlation coefficient is $(-0.030)$, which is a very weak correlation. Furthermore, the p-value for the statistical test of whether the correlation coefficient is significantly different from zero is (0.786). This is much greater than 0.05 (the level of statistical significance), so there is very weak evidence that the correlation is non-zero. This means that there is no significant correlation between the variables. Therefore, univariate control charts for each individual variable can be employed to monitor the process.



Fig. 6 Probability plot for pipe external diameter

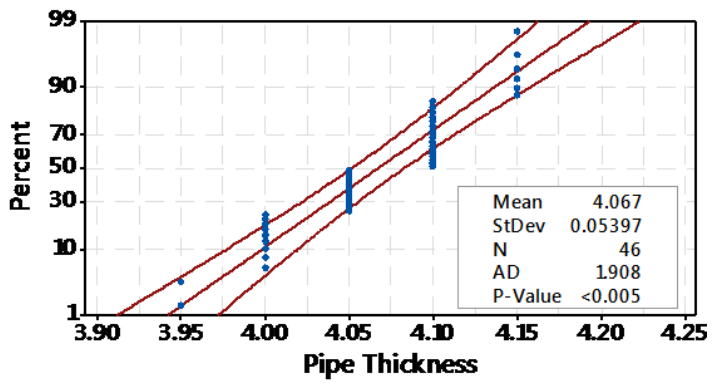

Fig. 7 Probability plot for pipe wall thickness

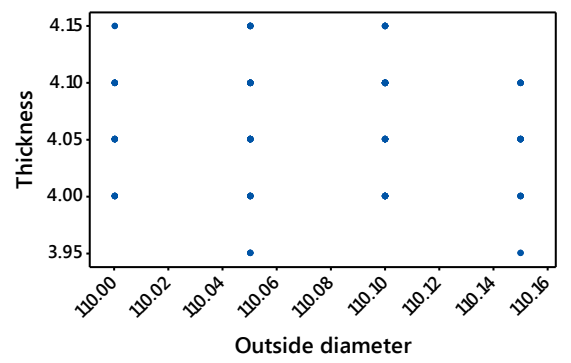

Fig. 8 Scatter plot of the pipe thickness versus its outside diameter 
With respect to the effect of non-normality on the $\bar{x}$ and R Charts, it has been indicated in Ref. [38] that sample sizes of four or five are sufficient to ensure reasonable robustness to the normality of the data. Therefore, the control charts will be directly constructed using the sampled data with no need for performing further transformation for the date. Fig. 9 and Fig. 10 illustrate the developed Shewhart $\bar{x}$ and $\mathrm{R}$ Charts for the pipe's external diameter and wall thickness, respectively. Examining the charts reveals that the process is in a state of statistical control.

In addition, the exponentially weighted moving average (EWMA) control charts have been constructed to assist in detecting small shifts in the process. For more details about the control limits equations for an EMWA char, one may refer to Ref. [38]. The EWMA charts (using a weight of 0.2) constructed for the pipe's external diameter and wall thickness are shown in Fig. 11 and Fig. 12, respectively. The developed charts have no out of control signals and these confirm that the process is in a state of statistical control.
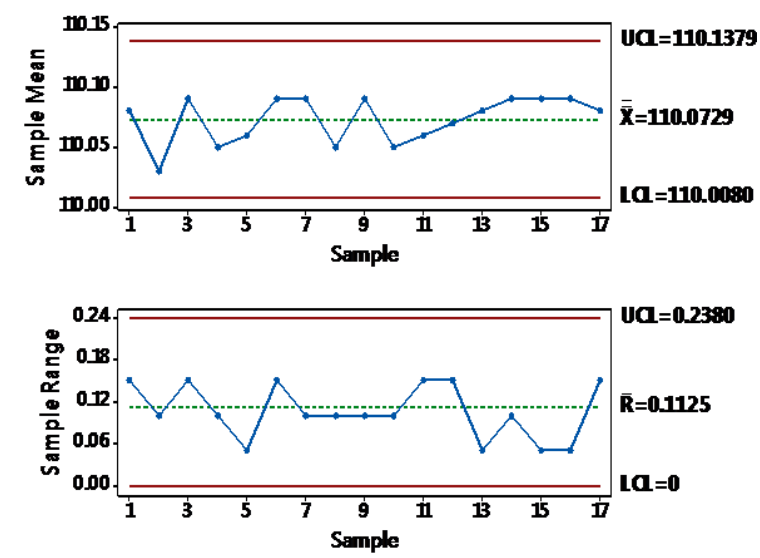

Fig. $9 \bar{x}$ and $\mathrm{R}$ chart for pipe's external diameter
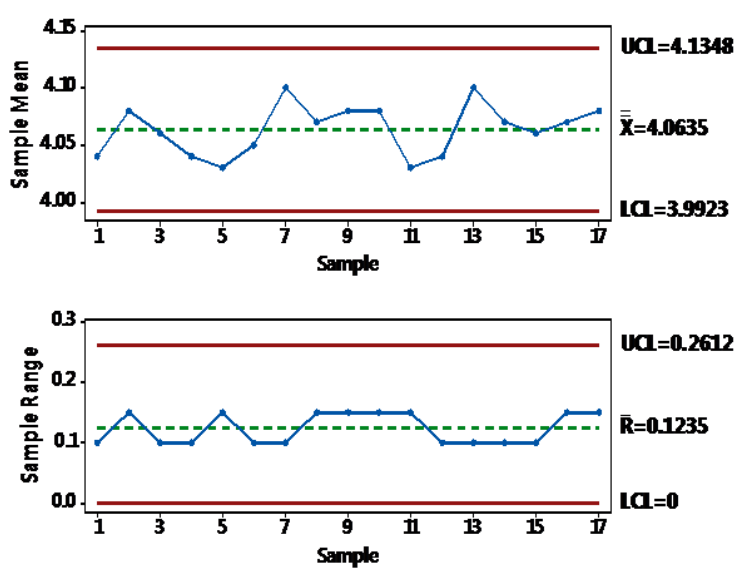

Fig. $10 \bar{x}$ and $\mathrm{R}$ chart for pipe's wall thickness



Fig. 11 EWMA chart for pipe's external diameter

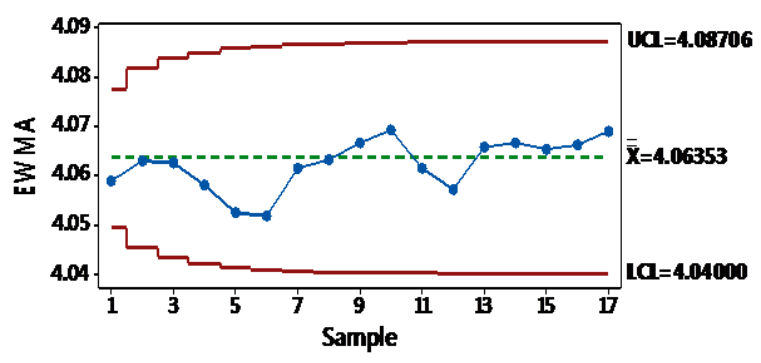

Fig. 12 EWMA chart for pipe's wall thickness

All the previous steps are known as phase I process control, in which the charts have been used as an aid to assess the stability of the process and to eliminate assignable causes if they exist. Once this has been achieved, the quality practitioners start to proceed to phase II. In phase II, the developed control charts are used for testing whether the process remains in control when future subgroups are drawn. In this case study, it is recommended that the factory should start adopting the developed charts to monitor the future production and the workers have to be trained to identify and interpret the out of control signals that could be observed. An out-ofcontrol-action-plan (OCAP) should be developed to assist in eliminating the assignable causes in a responsive manner. The OCAP should be frequently updated to serve as an active document containing all the latest guides to resolve production problems.

Considering the framework presented earlier in Fig. 1, in pipe extrusion there are several features and defects that can be monitored via visual inspection or can be observed depending on workers surveillance. These features include cracks, scratches, pinholes, tears, blisters, wrinkles, folds, sharp-edged grooves, as well as color variations. The workers should be trained and empowered to interfere to resolve either the out of control condition or the visually observed defects. Besides, the conditions in which the workers will be empowered to stop the line have to be precisely specified. Particularly, the conditions in which the process is expected to continue in producing defective items. Otherwise, they should be trained either to resolve the problem while the line is running or ask for assistance. 


\section{CONCLUSION}

This paper presents a framework that integrates the statistical process control with the worker empowerment practices to enhance the responsiveness toward detected defects as well as preventing the occurrence of more ones. The presented framework is a sociotechnical system that targets on incorporating the statistical approaches with the workers' skills. Thereby, it can help in decentralizing the quality related decision making in the production line which will result in a faster response to quality problems.

The framework has been adopted to monitor one of the UPVC pipe extrusion lines. In the presented case study, the characteristics to be monitored via control charts have identified and the appropriate control charts have been constructed. The performed analysis reveals that the process is in a state of statistical control and it has been recommended to use the developed charts for monitoring the process to help in identifying and eliminating assignable causes once they occur. Besides, the features to be monitored through workers' surveillance have been identified. It has been recommended to train the workers to identify the out of control conditions as well as the visually observed defects that necessitate their interference and also to empower them to stop the line as needed. The prompt response to the out of control signals as well as the pre-specified conditions that could result in producing defective items has the advantages of not only decreasing the defect rates but also decreasing the wasted resources. However, caution should be taken with empowering the workers to stop the line. It should be noted that stopping the line is only recommended if the line will continue to produce nonconforming parts until the current problem is resolved. Otherwise, stopping the line may adversely affect the line productivity.

\section{REFERENCES}

[1] R. Godina and J. C. Matias, "Improvement of the statistical process control through an enhanced test of normality," in Industrial Technology and Management (ICITM), 2018 7th International Conference on, 2018, pp. 17-21.

[2] R. J. Oakland and J. S. Oakland, Statistical Process Control: Taylor \& Francis, 2018.

[3] S. C. D. Perera, "Quality Analysis for uPVC pipes " Master of Science in Polymer Technology M.Sc., Department o f Chemical and Process Engineering University o f Moratuwa Srilanka 2003.

[4] C. C. Yang, T. M. Yeh, and K. J. Yang, "The implementation of technical practices and human factors of the toyota production system in different industries," Human Factors and
Ergonomics in Manufacturing \& Service Industries, vol. 22, pp. 541-555, 2012.

[5] C. R. Superville and S. Gupta, "Issues in modeling, monitoring and managing quality costs," The TQM magazine, vol. 13, pp. 419-424, 2001.

[6] S. P. Mukherjee, Quality-Domains and Dimensions. Singapore Springer, 2019.

[7] I. Madanhire and C. Mbohwa, "Application of statistical process control (SPC) in manufacturing industry in a developing country," Procedia Cirp, vol. 40, pp. 580-583, 2016.

[8] N. Fisher, Y. Tanaka, and W. Woodall, The Road to Quality Control: The Industrial Application of Statistical Quality Control by Homer M. Sarasohn: John Wiley \& Sons, 2019.

[9] Y. Klochkov, B. M. Alasas, A. Anand, and L. Papic, "Implementation of Six Sigma Methodology in Syrian Pharmaceutical Companies," in System Performance and Management Analytics, P. K. Kapur, Y. Klochkov, A. K. Verma, and G. Singh, Eds., ed Singapore: Springer Singapore, 2019, pp. 229240.

[10] G. Ö. Aşkın ÖZDAĞOĞLU , Mehmet Emre GÜLER3, " Developing Quality Control Charts for The Control Points of A Food Product," International Journal of Contemporary Economics and Administrative Sciences, vol. 8, pp. 89-113, 2018.

[11] V. Gupta, R. Jain, M. L. Meena, and G. S. Dangayach, "Six-sigma application in tiremanufacturing company: a case study," Journal of Industrial Engineering International, vol. 14, pp. 511-520, September 012018.

[12] D. Krumwiede and C. Sheu, "Implementing SPC in a small organization: a TQM approach," Integrated Manufacturing Systems, vol. 7, pp. 45-51, 1996.

[13] H. Lal and P. V. Kane, "Gearbox Fault Detection Using Exponentially Weighted Moving Average Control Charts," in Proceedings of iNaCoMM 2017, Machines, Mechanism and Robotics, Lecture Notes in Mechanical Engineering, Singapore, 2019, pp. 39-47.

[14] J. Thor, J. Lundberg, J. Ask, J. Olsson, C. Carli, K. P. Härenstam, et al., "Application of statistical process control in healthcare improvement: systematic review," BMJ Quality \& Safety, vol. 16, pp. 387-399, 2007.

[15] N. Mirzaei, S. Niroomand, and R. Zare, "Application of statistical process control in service industry: A case study of the restaurant sector," Journal of Modelling in Management, vol. 11, pp. 763-782, 2016.

[16]M. Ilbeigi, "Statistical process control for analyzing resilience of transportation networks," 
International Journal of Disaster Risk Reduction, vol. 33, pp. 155-161, 2019.

[17] J. H. Dulebohn, W. H. Bommer, R. C. Liden, R. L. Brouer, and G. R. Ferris, "A meta-analysis of antecedents and consequences of leader-member exchange: Integrating the past with an eye toward the future," Journal of management, vol. 38, pp. 1715-1759, 2012.

[18] K. J. Barker and C. R. Emery, "The effect of TQM factors on financial and strategic performance: an empirical test using manufacturing firms," Electronic Business, vol. 12, 2013.

[19] J. P. MacDuffie and J. Krafcik, "Integrating technology and human resources for highperformance manufacturing: Evidence from the international auto industry," Transforming organizations, vol. 209226, 1992.

[20] K. Hong, R. Nagarajah, P. Iovenitti, and M. Dunn, "A sociotechnical approach to achieve zero defect manufacturing of complex manual assemblies," Human Factors and Ergonomics in Manufacturing \& Service Industries, vol. 17, pp. 137-148, 2007.

[21] S. Mattsson, M. Karlsson, Å. Fast-Berglund, and I. Hansson, "Managing production complexity by empowering workers: six cases," Procedia Cirp, vol. 17, pp. 212-217, 2014.

[22] K. Birdi, C. Clegg, M. Patterson, A. Robinson, C. B. Stride, T. D. Wall, et al., "The impact of human resource and operational management practices on company productivity: A longitudinal study," Personnel Psychology, vol. 61, pp. 467-501, 2008.

[23] Y. Yin, Y. Wang, and Y. Lu, "Why firms adopt empowerment practices and how such practices affect firm performance? A transaction costexchange perspective," Human Resource Management Review, vol. 29, pp. 111-124, 2019.

[24]N. Duru Ahanotu, "Empowerment and production workers: a knowledge-based perspective," Empowerment in Organizations, vol. 6, pp. 177-186, 1998.

[25] S. Spear and H. K. Bowen, "Decoding the DNA of the Toyota production system," Harvard business review, vol. 77, pp. 96-106, 1999.

[26] S. Shingo and A. P. Dillon, A study of the Toyota production system: From an Industrial Engineering Viewpoint: CRC Press, 1989.
[27] ISO-3126, Plastics piping systems-Plastics components-Determination of dimensions: International Organization for Standardization, 2005.

[28] Minitab-Inc., "Minitab Statistical Software ", 17 ed: (www.minitab.com), 2010.

[29] D. C. Montgomery and C. M. Mastrangelo, "Some statistical process control methods for autocorrelated data," Journal of Quality Technology, vol. 23, pp. 179-193, 1991.

[30] C. A. Lowry and D. C. Montgomery, "A review of multivariate control charts," IIE transactions, vol. 27, pp. 800-810, 1995.

[31] S. Bersimis, S. Psarakis, and J. Panaretos, "Multivariate statistical process control charts: an overview," Quality and Reliability engineering international, vol. 23, pp. 517-543, 2007.

[32] R. L. Mason and J. C. Young, Multivariate statistical process control with industrial applications: Society for Industrial and Applied Mathematics, 2002.

[33] S. Bersimis, J. Panaretos, and S. Psarakis, "Multivariate statistical process control charts and the problem of interpretation: a short overview and some applications in industry," in Proceedings of the 7th Hellenic European Conference on Computer Mathematics and its Applications, Athens, Greece, 2005.

[34] K. R. Das and A. Imon, "A brief review of tests for normality," American Journal of Theoretical and Applied Statistics, vol. 5, pp. 5-12, 2016.

[35] J. B. Carroll, "The nature of the data, or how to choose a correlation coefficient," Psychometrika, vol. 26, pp. 347-372, 1961.

[36] R. L. Fowler, "Power and robustness in productmoment correlation," Applied Psychological Measurement, vol. 11, pp. 419-428, 1987.

[37] A. J. Bishara and J. B. Hittner, "Testing the significance of a correlation with nonnormal data: comparison of Pearson, Spearman, transformation, and resampling approaches," Psychological methods, vol. 17, p. 399, 2012.

[38] D. C. Montgomery, Introduction to statistical quality control: John Wiley \& Sons, 2007. 